Electrical \& Computer Engineering: An International Journal (ECIJ) Volume 2, Number 3, September 2013

\title{
A Multipurpose Matrices Methodology for TRANSMISSION USAGE, LOSS AND RELIABILITY MARgIN ALLOCATION IN RESTRUCTURED ENVIRONMENT
}

\author{
Baseem Khan, Ganga Agnihotri, Gaurav Gupta \\ Department of Electrical Engineering, MANIT, Bhopal, India
}

\begin{abstract}
In the era of power system restructuring there is a need of simplified method which provides a complete allocation of usage, transmission losses and transmission reliability margin. In this paper, authors presents a combined multipurpose matrices methodology for Transmission usage, transmission loss and transmission reliability margin allocation. Proposed methodology is simple and easy to implement on large power system. A modified Kirchhoff matrix is used for allocation purpose. A sample 6 bus system is used to demonstrate the feasibility of proposed methodology.
\end{abstract}

\section{KEYWORDS}

Modified Kirchhoff Matrix, Transmission usage, Transmission Loss, Transmission Reliability Margin.

\section{NOMENCLATURE}

$\mathrm{pf}_{\mathrm{ij}}=$ Elements of Power Flow Matrix

$\mathrm{p}_{\mathrm{ij}}=$ Active Power in Branch $\mathrm{i}-\mathrm{j}$ from Bus i to Bus $\mathrm{j}$

$\mathrm{p}_{\mathrm{Ti}}=$ Net Flows on the Nodes

$\mathrm{K}_{\mathrm{m}}=$ Modified Kirchhoff Matrix

$\mathrm{k}_{\mathrm{ij}}^{\mathrm{m}}=$ Elements of Modified Kirchhoff Matrix

$\mathrm{kl}_{\mathrm{ij}}=$ Elements of Kirchhoff Loss Matrix

$\mathrm{p}_{\mathrm{ij}}^{\mathrm{l}}=$ Transmission Loss in Line i-j in Actual Direction

$p_{j i}^{l}=$ Transmission Loss in Line $i-j$ in Counter Direction

I= Identity Matrix

$\mathrm{P}_{\mathrm{L}}=$ Active Load Power

$\mathrm{P}_{\mathrm{G}}=$ Active Generation

$\mathrm{P}_{\mathrm{GG}}=$ Number of Generators in Diagonal Matrix

SFM= Supply Factor Matrix

$\mathrm{t}_{\mathrm{ij}}=$ Elements of Supply Factor Matrix

$\mathrm{P}_{\mathrm{LL}}=$ Number of Loads in Diagonal Matrix

EFM= Extraction Factor Matrix

$\mathrm{p}_{\mathrm{sb}}^{\mathrm{l}}=$ Loss in s-b Line

$r_{j s}=$ Elements of Extraction Factor Matrix

$\mathrm{P}_{\mathrm{i} \rightarrow \mathrm{s}-\mathrm{b}}^{\mathrm{l}}=$ Share of Generator $\mathrm{i}$ in the Transmission Loss of Line s-b

$\mathrm{p}_{\mathrm{s}-\mathrm{b}}=$ Power Loss in Transmission Line $\mathrm{s}-\mathrm{b}$ 
Electrical \& Computer Engineering: An International Journal (ECIJ) Volume 2, Number 3, September 2013

\section{INTRODUCTION}

In deregulated electricity market, issues like usage allocation, loss allocation, transmission pricing, congestion management etc. are of great importance. Several methodologies have been proposed for the allocation of usage, loss and transmission reliability margin (TRM). But every methodology has its own limitation. Some of them (e.g., postage stamp, contract path, MW-Mile) are based on the actual network usage of a transaction and are addressed as embedded methods, while others (marginal/incremental) are based on the additional transmission cost that is caused by a specific electricity transaction [27]. In a restructured market structure seller and buyer made no direct transaction. Hence the usage allocation between them is made by power flow tracing methods, used to calculate the contribution of each user (generator or load) to each line flow.

Colombia, UK and Brazil, have used long run marginal cost (LRMC) methodology due to its easy implementation. Selection of the slack bus greatly influenced the pricing methodologies, such as use of a fixed "slack bus" is adequate in countries where most of the load is concentrated in a single centre, such as the cities Buenos Aires (Argentina) and Santiago (Chile). Hence the marginal participation method is applied in countries like Argentina, Chile and Panama.

In India the method which is used so far is Postage stamp method. But this method is not distance and direction sensitive. It is mainly depending on the amount of transacted power. The main advantage of this method is its simplicity in implementation. Due to its various demerits central electricity regulatory commissions (CERC) of India proposed a new transmission pricing methodology which is the combination of power flow tracing technique and marginal participation methodology. In the proposed hybrid methodology power flow tracing is used for selection of the "slack bus" while by marginal participation burden of transmission charges or losses on each node is computed.

Due to deregulation, the capacity margins of transmission lines is reduced because the number of participates on electric grid is increased. Hence grid ability to transfer power from generation to load within permissible voltage and frequency limits is also greatly decreased. So the transmission embedded cost allocation methodologies should consider all these factors [15]. For this purpose a factor related to transmission reliability margin should be added in transmission pricing mechanism to address issues related to transmission network reliability.

There are various transmission pricing methodologies, which are used across the world for allocation of transmission charges to users. These are mainly classified into the embedded cost, and market based pricing methodologies. Embedded Cost Pricing methods are based upon determining a utility's total cost of providing the transmission services. It includes service, asset, and operation \& maintenance costs. While the market based pricing methodologies are driven by a competitive bidding process which results in prices that are influenced by the demand of services. Power flow tracing methods of cost allocation are comes under the embedded cost pricing. These provide us a complete view of the usage allocation problem which is very important for transmission cost allocation. When usage allocation is known it is straightforward to allocate the transmission cost to generators and loads. The first attempt to trace power flows was done by Bialek et al. when topological generation distribution factors based power flow tracing were proposed in March 1996 [1], which explained the method for tracing generator's output. In Feb 1997, Kirschen et al. [2] explained a power flow tracing method based on the proportional sharing assumption which introduces the concept of domains, Commons, and links. In Nov 2000, Gubina et al. [3] described the method to determine the generators' contribution to a particular load by using the nodal generation distribution factors. In Aug 2000, Wu et al. [4] explained the use of graph theory to calculate the contributions of individual generators and loads to line flows and the real power transfer between distinctive generators and loads. In 2009, Xie et 
al.[5] proposed power flow tracing algorithm founded in the extended incidence matrix considering loop flows. In Feb 2007, Conejo et al. [6] explained a method of network cost allocation based on Z-bus matrix.

Further, the existing loss allocation methods may be classified into prorata, marginal, power flow tracing, and circuit theory based methods. Prorata method is characterized by the allocation of electric losses proportionally to the power delivered by each generator and each load. It is also assumed an equal allocation $50 \%$ to generator and 50\% of the loads [7]. In marginal procedure, incremental transmission coefficients are used for allocation of transmission losses to demands and generators [8]. The use of power flow tracing methods for allocation of transmission losses is proposed in [9]. In circuit theory based method, A. J. Conejo et al. proposed a Z- bus matrix for transmission loss allocation. This method presents a new procedure for allocating transmission losses to generators and loads in the context of pools operated under a single marginal price derived from a merit-order approach [10]. The main difficulty in allocating losses to load or generator to bilateral contracts by circuit theory is that, despite approximations, the final allocations always contain a certain degree of arbitrariness. Recently several new algorithms and methods have been also proposed such as in [11] a method based on complex power flow tracing is proposed. In [12] author decomposed transmission losses into three components and characterizes them. A method based on a combination of cooperative game theory and circuit theory is presented in [13].

Due to deregulation, the number of interaction entitles on the electric grid increases dramatically. At the same time capacity margin reduced. Hence this rapid growth threatened reliability of transmission network greatly. That's why transmission reliability margin allocation should be addressed in a fair way. Many researchers proposed methodology which incorporate reliability cost element in total transmission cost. For this first usage and TRM allocation is done. In [14] Silva et al. considered the transmission network operation under normal as well as contingency condition for allocation reliability cost to users. In [15-16] D. Hur et al. proposed various variants of procedures to allocate reliability contribution to market participants. In [17] V. Vijay et al. proposed a novel probabilistic transmission pricing methodology with consideration to transmission reliability margin. In $2008 \mathrm{H}$. Monsef et al. [18] presented the transmission cost allocation based on use of reliability margin under contingency condition. For this purpose a probability index is defined.

In this paper, authors presents a combined multipurpose matrices methodology for Transmission usage, transmission loss and transmission reliability margin allocation.

\section{Proposed Matrices Methodology}

Let consider a simple diagraph $\mathrm{G}$ showed in fig. 1 [21]. 
Electrical \& Computer Engineering: An International Journal (ECIJ) Volume 2, Number 3, September 2013

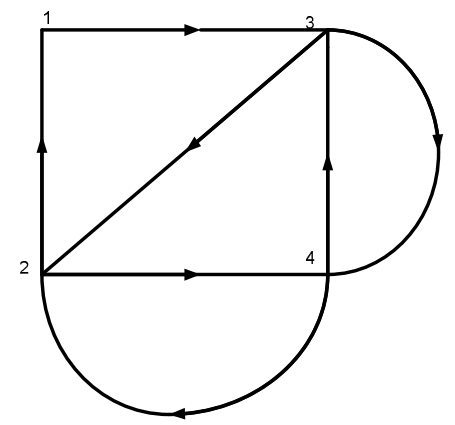

Fig. 1: A Simple Diagraph G

The Kirchhoff matrix of above diagraph is given by Eq. 1.

$$
\mathrm{K}(\mathrm{G})=\left[\begin{array}{cccc}
1 & 0 & -1 & 0 \\
-1 & 2 & 0 & -1 \\
0 & -1 & 2 & -1 \\
0 & -1 & -1 & 2
\end{array}\right]
$$

Hence from the above example for a simple digraph ${ }^{\mathrm{G}}$ of ${ }^{\mathrm{n}}$ vertices, an ${ }^{\mathrm{n}}$ by ${ }^{\mathrm{n}}$ matrix called the Kirchhoff matrix $\mathrm{K}(\mathrm{G})$ or $\mathrm{K}=\left[\mathrm{k}_{\mathrm{ij}}\right]$ is defined as $[21]$,

$$
K= \begin{cases}d^{-}\left(v_{i}\right) & \text { for } i=j \\ -x_{i j} & \text { for } i \neq j\end{cases}
$$

Where $\quad d^{-}\left(v_{i}\right)=$ in-degree of the ith vertex

$$
-\mathrm{x}_{\mathrm{ij}}=(\mathrm{i}, \mathrm{j}) \text { th entry in the adjacency matrix }
$$

This matrix is the basis of the proposed methodology.

Firstly, authors construct a power flow matrix from the Newton Raphson load flow. This matrix gives a complete overview of power flows in the system. It is formed between nodes of the system. Diagonal elements give net flows at nodes and off diagonal elements give the actual flows and counter flows in the system. The proposed matrix is defined as follows:

\section{Where}

$$
\mathrm{pf}_{\mathrm{ij}}=\left\{\begin{array}{lr}
-\mathrm{p}_{\mathrm{ij}} & \text { for } \mathrm{i} \neq \mathrm{j} \text { and } \mathrm{p}_{\mathrm{ij}}>0 \\
\mathrm{p}_{\mathrm{ij}} & \text { for } \mathrm{i} \neq \mathrm{j} \text { and } \mathrm{p}_{\mathrm{ji}}>0 \\
\mathrm{p}_{\mathrm{Ti}} & \text { for } \mathrm{i}=\mathrm{j}
\end{array}\right.
$$

$\mathrm{p}_{\mathrm{ij}}(>0)=$ active power in branch $\mathrm{i}-\mathrm{j}$ from bus ${ }^{\mathfrak{i}}$ to bus $\mathfrak{j}$

From the above matrix and using eq.1 the Modified Kirchhoff matrix is constructed as follows: Denoting Modified Kirchhoff matrix of a Power Network as $K_{m}=\left(k_{i j}^{m}\right)_{n \times n}$, the authors define the following expression for elements of the Modified Kirchhoff matrix: 
Electrical \& Computer Engineering: An International Journal (ECIJ) Volume 2, Number 3, September 2013

$$
\mathrm{k}_{\mathrm{ij}}^{\mathrm{m}}=\left\{\begin{array}{cc}
-\mathrm{p}_{\mathrm{ij}} & \text { for } \mathrm{i} \neq \mathrm{j} \text { and } \mathrm{p}_{\mathrm{ij}}>0 \\
\mathrm{p}_{\mathrm{Ti}} & \text { for } \mathrm{i}=\mathrm{j} \\
0 & \text { otherwise }
\end{array}\right.
$$

Now from the above Modified Kirchhoff matrix, Kirchhoff loss matrix can be formed as follows:

Where

$$
\mathrm{kl}_{\mathrm{ij}}=\left\{\begin{array}{rr}
\mathrm{p}_{\mathrm{ij}}^{\mathrm{l}} & \text { for } \mathrm{i} \neq \mathrm{j} \text { and } \mathrm{p}_{\mathrm{ij}}>\mathrm{p}_{\mathrm{ji}} \text { and } \mathrm{p}_{\mathrm{ji}}<0<\mathrm{p}_{\mathrm{ij}} \\
\mathrm{p}_{\mathrm{ji}}^{\mathrm{l}} & \text { for } \mathrm{i} \neq \mathrm{j} \text { and } \mathrm{p}_{\mathrm{ji}}>\mathrm{p}_{\mathrm{ij}} \text { and } \mathrm{p}_{\mathrm{ij}}<0<\mathrm{p}_{\mathrm{ji}} \\
0 & \text { otherwise }
\end{array}\right.
$$

$$
p_{i j}^{l}=p_{i j}+p_{j i} \text {, and } p_{j i}^{l}=p_{j i}+p_{i j}
$$

\subsection{Properties of Modified Kirchhoff matrix}

Property.1: The sum of all elements in the row $\mathrm{j}$ of a Modified Kirchhoff matrix equals the active load power at bus j i.e [5].

$$
\mathrm{K}_{\mathrm{m}} \mathrm{I}=\mathrm{P}_{\mathrm{L}}
$$

Property.2: The sum of all elements in the column $\mathrm{j}$ of a Modified Kirchhoff matrix equals the total active power of generators at bus $j$ i.e.

$$
\mathrm{I}^{\mathrm{T}} \mathrm{K}_{\mathrm{m}}=\left(\mathrm{P}_{\mathrm{G}}\right)^{\mathrm{T}}
$$

The above equation can be rewritten as follows

$$
\mathrm{K}_{\mathrm{m}}^{\mathrm{T}} \mathrm{I}=\mathrm{P}_{\mathrm{G}}
$$

From equations (5) and (7) we have

$$
\begin{aligned}
& \mathrm{I}=\mathrm{K}_{\mathrm{m}}{ }^{-1} \mathrm{P}_{\mathrm{L}} \\
& \mathrm{I}=\left(\mathrm{K}_{\mathrm{m}}{ }^{\mathrm{T}}\right)^{-1} \mathrm{P}_{\mathrm{G}}
\end{aligned}
$$

eq. (9) can be rewritten as

$$
\mathrm{I}=\left(\mathrm{K}_{\mathrm{m}}{ }^{-1}\right)^{\mathrm{T}} \mathrm{P}_{\mathrm{G}}
$$

From the above matrix, inverse of Modified Kirchhoff matrix $\left(\mathrm{K}_{\mathrm{m}}^{-1}\right)$ is obtained which is used for power flow tracing and transmission loss allocation. In the next section procedure of power flow tracing and transmission loss allocation is described.

\section{Procedure for Tracing Power Flow and Loss Allocation}

In this paper authors adopt the tracing procedure which is proposed in [5]. But authors modified this tracing algorithm for transmission loss and reliability margin allocation. 
Electrical \& Computer Engineering: An International Journal (ECIJ) Volume 2, Number 3, September 2013

\subsection{Model for Power flow Tracing}

Let $\ln =1 \ldots \ldots . . \mathrm{e}$ represents the total number of lines in the system. $\mathrm{Gn}=1 \ldots \ldots . . \mathrm{g}$ is the total number of generators and $\mathrm{D}=1 \ldots \ldots \mathrm{d}$ is the total number of loads in the system.

Again let $\mathrm{P}_{\mathrm{GG}}=\operatorname{diag}\left(\mathrm{P}_{\mathrm{G} 1}, \mathrm{P}_{\mathrm{G} 2}, \ldots, \mathrm{P}_{\mathrm{Gg}}\right)$ represents the number of generators in diagonal matrix. Thus

$$
\mathrm{I}^{\mathrm{T}} \mathrm{P}_{\mathrm{GG}}=\left(\mathrm{P}_{\mathrm{G}}\right)^{\mathrm{T}} \text { or } \mathrm{P}_{\mathrm{G}}=\mathrm{P}_{\mathrm{GG}} \mathrm{I}
$$

combining eqs. (11) and (8)

$$
\mathrm{P}_{\mathrm{G}}=\mathrm{P}_{\mathrm{GG}} \mathrm{K}_{\mathrm{m}}^{-1} \mathrm{P}_{\mathrm{L}}
$$

Matrix $\mathrm{P}_{\mathrm{GG}} \mathrm{K}_{\mathrm{m}}{ }^{-1}$ is named supply factor matrix. The supply factor matrix is denoted by $\mathrm{SFM}=$ $\left(t_{i j}\right)$, i. e.,

$$
\mathrm{SFM}=\mathrm{P}_{\mathrm{GG}} \mathrm{K}_{\mathrm{m}}{ }^{-1}
$$

and from eq. (9)

$$
P_{G i}=\sum_{j=1}^{n} t_{i j} P_{L j}
$$

Where $t_{i j} P_{L j}$ denotes the active power distribution of generation output at bus $i$ to the load situated at bus $\mathrm{j}[5]$.

$$
P_{i \rightarrow j}=t_{i j} P_{L j}
$$

Thus eq. (15) gives the generator's share to loads in the system.

On the same line for calculating the generators shares to lines flow eq. (15) is modified by replacing load power from the lines flow as shown in eq. (16). It is assumed that a $a_{\text {gen }}$ : $a_{\text {load }}$ (23:77) split in the transmission usage occurs between generators and demand [19].

For the generator share situated at bus s to the line s-b is given by

$$
\mathrm{P}_{\mathrm{i} \rightarrow \mathrm{s}-\mathrm{b}}=\mathrm{t}_{\mathrm{is}} \mathrm{P}_{\mathrm{sb}} \mathrm{a}_{\text {gen }}
$$

Eqs. (15) and (16) gives the generators share in loads and lines flows. Similarly, the usage allocated to a load for the use of all lines can be defined by using $\mathrm{a}_{\text {load }}$ instead of $\mathrm{a}_{\text {gen }}$.

For calculating the loads shares in line flows and generated power same procedure is followed:

Considering dual of eq. (9)

$$
\mathrm{P}_{\mathrm{L}}=\mathrm{P}_{\mathrm{LL}}\left(\mathrm{K}_{\mathrm{m}}^{-1}\right)^{\mathrm{T}} \mathrm{P}_{\mathrm{G}}
$$

Where the diagonal matrix $\mathrm{P}_{\mathrm{LL}}=\operatorname{diag}\left(\mathrm{P}_{\mathrm{L} 1}, \mathrm{P}_{\mathrm{L} 2}, \ldots, \mathrm{P}_{\mathrm{Ld}}\right)$ and $\mathrm{EFM}=\mathrm{P}_{\mathrm{LL}}\left(\mathrm{K}_{\mathrm{m}}{ }^{-1}\right)^{\mathrm{T}}$ is the extraction factor matrix of loads from generators [5].

By using an EFM, loads share in generating power and line flows is calculated. 
Electrical \& Computer Engineering: An International Journal (ECIJ) Volume 2, Number 3, September 2013

\subsection{Model for Transmission Loss}

For transmission loss allocation to generator considers eq. (16). In this equation line flows $\mathrm{P}_{\mathrm{sb}}$ is replaced by the transmission Loss in lines which is coming from the elements of the Kirchhoff loss matrix $\mathrm{p}_{\mathrm{ij}}^{\mathrm{l}}$ and $\mathrm{p}_{\mathrm{ji}}^{\mathrm{l}}$.

Hence transmission losses of line s-b allocated to generator located at bus $\mathrm{i}$ is given by:

$$
\mathrm{P}_{\mathrm{i}-\mathrm{s} \rightarrow \mathrm{b}}^{\mathrm{l}}=\mathrm{t}_{\mathrm{is}} \mathrm{p}_{\mathrm{sb}}^{\mathrm{l}}
$$

Similarly transmission losses of line s-b allocated to load situated at bus $\mathrm{j}$ is given by:

$$
P_{j \rightarrow s-b}^{l}=r_{j s} p_{s b}^{l}
$$

From the equations (18) and (19) losses are allocated to generators and loads respectively. This method of loss allocation is said to be direct because all the calculation is already done for usage allocation.

\subsection{Model for Transmission Reliability Allocation}

For transmission reliability margin allocation to generator and load, considered eq. 16,

$\mathrm{TRM}=$ maximum capacity of the line in p.u. - usage of the line in p.u.

$$
\mathrm{TRM}_{\mathrm{ij}}=1-\mathrm{pf}_{\mathrm{ij}}
$$

Where for a particular line the calculation of TRM has considered Maximum capacity of the all line is $1 \mathrm{p} . \mathrm{u}$

In this equation line flows $\mathrm{P}_{\mathrm{sb}}$ is replaced by the transmission reliability margins in lines which is coming from the elements of TRM $\mathrm{Tij}_{\mathrm{ij}}$.

Hence transmission reliability margin of line s-b allocated to generator located at bus $i$ is given by:

$$
\mathrm{TRM}_{\mathrm{i}-\mathrm{s} \rightarrow \mathrm{b}}^{\mathrm{l}}=\mathrm{t}_{\mathrm{is}} \operatorname{trm}_{\mathrm{sb}}^{\mathrm{l}}
$$

Similarly transmission reliability margin of line s-b allocated to load situated at bus $\mathrm{j}$ is given by:

$$
\mathrm{TRM}_{\mathrm{j} \rightarrow \mathrm{s}-\mathrm{b}}^{\mathrm{l}}=\mathrm{r}_{\mathrm{js}} \operatorname{trm}_{\mathrm{sb}}^{\mathrm{l}}
$$

From the equations (21) and (22) TRM are allocated to generators and loads respectively.

\section{RESUlt AND DisCUSSION}

The proposed matrices methodology is applied to the sample 6 bus system presented in [26] bus power system to demonstrate the feasibility and effectiveness of the methodology. A computer program coded in MATLAB is developed. 
Electrical \& Computer Engineering: An International Journal (ECIJ) Volume 2, Number 3, September 2013

\subsection{Transmission Usage Allocation}

The sample 6 bus power system is used to illustrate the proposed methodology. Table 1 gives the generators contributions to line flows. These tables also provide the transmission charge allocation to generators.

\begin{tabular}{|c|c|c|c|c|}
\hline Line & Flow(pu) & $\begin{array}{c}\text { Supplied by } \\
\text { Gen.1(pu) }\end{array}$ & $\begin{array}{c}\text { Supplied by } \\
\text { Gen.2(pu) }\end{array}$ & $\begin{array}{c}\text { Supplied by } \\
\text { Gen.3(pu) }\end{array}$ \\
\hline $1-2$ & 0.29 & 0.29 & 0.00 & 0.00 \\
\hline $1-4$ & 0.44 & 0.44 & 0.00 & 0.00 \\
\hline $1-5$ & 0.36 & 0.36 & 0.00 & 0.00 \\
\hline $2-3$ & 0.03 & 0.01 & 0.02 & 0.00 \\
\hline $2-4$ & 0.33 & 0.12 & 0.21 & 0.00 \\
\hline $2-5$ & 0.16 & 0.06 & 0.10 & 0.00 \\
\hline $2-6$ & 0.26 & 0.10 & 0.17 & 0.00 \\
\hline $3-5$ & 0.19 & 0.00 & 0.01 & 0.18 \\
\hline $3-6$ & 0.44 & 0.01 & 0.01 & 0.42 \\
\hline $4-5$ & 0.04 & 0.03 & 0.01 & 0.00 \\
\hline $5-6$ & 0.02 & 0.01 & 0.00 & 0.00 \\
\hline
\end{tabular}

Table.1: Transferred Power Allocated to Generators for 6 Bus System

Similarly, the Extraction factor matrix (EFM) is formulated for calculating the power extracted by the loads from the generator bus and line flows.

Table 2 provides the transmission line flows allocated to loads.

\begin{tabular}{|c|c|c|c|c|}
\hline Line & Flow & $\begin{array}{c}\text { Extracted } \\
\text { by Load4 } \\
(\mathrm{pu})\end{array}$ & $\begin{array}{c}\text { Extracted } \\
\text { byLoad5 } \\
(\mathrm{pu})\end{array}$ & $\begin{array}{c}\text { Extracted } \\
\text { byLoad6 } \\
(\mathrm{pu})\end{array}$ \\
\hline $1-2$ & 0.29 & 0.14 & 0.12 & 0.03 \\
\hline $1-4$ & 0.44 & 0.21 & 0.18 & 0.05 \\
\hline $1-5$ & 0.36 & 0.17 & 0.14 & 0.04 \\
\hline $2-3$ & 0.03 & 0.01 & 0.01 & 0.01 \\
\hline $2-4$ & 0.33 & 0.13 & 0.08 & 0.12 \\
\hline $2-5$ & 0.16 & 0.06 & 0.04 & 0.06 \\
\hline $2-6$ & 0.26 & 0.11 & 0.06 & 0.10 \\
\hline $3-5$ & 0.19 & 0.00 & 0.06 & 0.14 \\
\hline $3-6$ & 0.44 & 0.00 & 0.13 & 0.31 \\
\hline $4-5$ & 0.04 & 0.04 & 0.00 & 0.00 \\
\hline $5-6$ & 0.02 & 0.00 & 0.02 & 0.00 \\
\hline
\end{tabular}

Table.2: Extracted Power Allocated to Loads for 6 Bus System 
Electrical \& Computer Engineering: An International Journal (ECIJ) Volume 2, Number 3, September 2013

\subsection{Transmission Loss Allocation}

Table 3 gives a transmission loss allocation to loads and generators. Total system losses occurred in the system is $0.0847 \mathrm{pu}$ from which $23 \%$ is allocated to generators and $77 \%$ is allocated to demands.

\begin{tabular}{|c|c|c|c|c|c|c|c|}
\hline Lines & Loss & L4 & L5 & L6 & G1 & G2 & G3 \\
\hline $1-2$ & 0.0094 & 0.0035 & 0.0029 & 0.0008 & 0.0022 & 0.0000 & 0.0000 \\
\hline $1-4$ & 0.0113 & 0.0042 & 0.0035 & 0.0009 & 0.0026 & 0.0000 & 0.0000 \\
\hline $1-5$ & 0.0112 & 0.0042 & 0.0035 & 0.0009 & 0.0026 & 0.0000 & 0.0000 \\
\hline $2-3$ & 0.0004 & 0.0001 & 0.0001 & 0.0001 & 0.0000 & 0.0001 & 0.0000 \\
\hline $2-4$ & 0.0164 & 0.0051 & 0.0029 & 0.0047 & 0.0014 & 0.0024 & 0.0000 \\
\hline $2-5$ & 0.0056 & 0.0017 & 0.0010 & 0.0016 & 0.0005 & 0.0008 & 0.0000 \\
\hline $2-6$ & 0.0062 & 0.0019 & 0.0011 & 0.0018 & 0.0005 & 0.0009 & 0.0000 \\
\hline $3-5$ & 0.0123 & 0.0000 & 0.0028 & 0.0066 & 0.0001 & 0.0001 & 0.0027 \\
\hline $3-6$ & 0.0108 & 0.0000 & 0.0025 & 0.0058 & 0.0000 & 0.0001 & 0.0024 \\
\hline $4-5$ & 0.0004 & 0.0003 & 0.0000 & 0.0000 & 0.0001 & 0.0000 & 0.0000 \\
\hline $5-6$ & 0.0006 & 0.0000 & 0.0005 & 0.0000 & 0.0001 & 0.0000 & 0.0000 \\
\hline Total & 0.0847 & 0.0211 & 0.0208 & 0.0233 & 0.0100 & 0.0044 & 0.0051 \\
\hline
\end{tabular}

Table.3: Transmission Loss Allocation

\subsection{Transmission Reliability Margin Allocation}

From the equations (21) and (22) TRM are allocated to generators and loads respectively. From the table 4 it is observed that the generators which contribute more power to line flows, have more TRM allocated.

\begin{tabular}{|c|c|c|c|c|}
\hline Line & TRM & G1 & G2 & G3 \\
\hline $1-2$ & 0.608 & 0.608 & 0 & 0 \\
\hline $1-4$ & 0.420 & 0.42 & 0 & 0 \\
\hline $1-5$ & 0.617 & 0.617 & 0 & 0 \\
\hline $2-3$ & 0.956 & 0.3537 & 0.61184 & 0 \\
\hline $2-4$ & 0.596 & 0.22052 & 0.38144 & 0 \\
\hline $2-5$ & 0.803 & 0.2967 & 0.51392 & 0 \\
\hline $2-6$ & 0.683 & 0.2527 & 0.43712 & 0 \\
\hline $3-5$ & 0.747 & 0.01494 & 0.02241 & 0.70965 \\
\hline $3-6$ & 0.488 & 0.00976 & 0.01464 & 0.4636 \\
\hline $4-5$ & 0.922 & 0.70072 & 0.26738 & 0 \\
\hline $5-6$ & 0.907 & 0.57141 & 0.14512 & 0.23582 \\
\hline
\end{tabular}

Table.4: Transmission Loss Allocation

\section{CONCLUSIONS}

This paper presents a combined methodology for transmission usage, loss and reliability margin allocation. A simple Kirchhoff matrix is used for this purpose. Various authors provide many methods for addressing such issues but none of them addresses all these issues collectively. Also 
Electrical \& Computer Engineering: An International Journal (ECIJ) Volume 2, Number 3, September 2013

all the calculation is done only single time for all these allocation. Proposed method can be applied to a large power system with FACTS devices. A sample 6 bus system is used to demonstrate the feasibility of proposed methodology.

\section{ACKNOWLEDGEMENTS}

The authors would like to thank everyone, just everyone!

\section{REFERENCES}

[1] Lee, J. Bialek, D. B. Tam, “Tracing The Generators' Output”, Opportunities and Advances in International Power Generation, 18-20th March 1996.

[2] Daniel Kirschen Ron Allan Goran Strbac, "Contributions of Individual Generators to Loads and Flows”, IEEE Transactions on Power Systems, Vol. 12, No. 1, February 1997.

[3] Ferdinand Gubina, David Grgic, Ivo Bani, "A Method for Determining the Generators' Share in a Consumer Load", IEEE transactions on power systems, vol. 15, no. 4, November 2000.

[4] Felix F. Wu, Yixin Ni, and Ping Wei, "Power Transfer Allocation for Open Access Using Graph Theory - Fundamentals and Applications in Systems without Loop flow", IEEE transactions on power systems, vol. 15, no. 3, august 2000.

[5] Kaigui Xie, Jiaqi Zhou, Wenyuan Li, "Analytical model and algorithm for tracing active power flow based on extended incidence matrix" Electric Power Systems Research 79 (2009) 399-405.

[6] Antonio J. Conejo, Javier Contreras, Delberis A. Lima, Antonio Padilha-Feltrin, "Z-bus Transmission Network Cost Allocation”, IEEE transactions on power systems, vol. 22, no. 1, February 2007.

[7] A. J. Conejo, J. M. Arroyo, N. Alguacil, and A. L. Guijarro, "Transmission Loss Allocation: A Comparison of Different Practical Algorithms", IEEE Trans. Power Syst., VOL. 17, NO. 3, AUGUST 2002.

[8] J. J. González and P. Basagoiti, "Spanish power exchange market and information system. Design concepts, and operating experience," in Proc. IEEE PICA Conf., Santa Clara, CA, May 1999, pp. $245-252$.

[9] J. W. Bialek, S. Ziemianek, and N. Abi-Samra, "Tracking-based loss allocation and economic dispatch," in Proc. 13th PSCC, Trondheim, Norway, June/July 1999, pp. 375-381.

[10] A. J. Conejo, F. D. Galiana, and I. Kockar, "Z-bus loss allocation,” IEEE Trans. Power Syst., vol. 16, pp. 105-110, Feb. 2001.

[11] S. Abdelkader, "Transmission loss allocation through complex power flow tracing," IEEE Trans. Power Syst., vol. 22, no. 4, pp. 2240-2248, Nov. 2007.

[12] S. Abdelkader, "Characterization of transmission losses" IEEE Trans. Power Syst., vol. 26, no. 1, February 2011.

[13] Yuri P. Molina, Ricardo B. Prada, and Osvaldo R. Saavedra, "Complex Losses Allocation to Generators and Loads Based on Circuit Theory and Aumann-Shapley Method", IEEE Trans. Power Syst., VOL. 25, NO. 4, NOVEMBER 2010.

[14] SILVA E.L., MESA S.E.C., MOROZOWSKI M.: 'Transmission access pricing to wheeling transactions: a reliability based approach', IEEE Trans. Power Syst., 1998, 13, (4), pp. 1481-1486.

[15] D. Hur, C.-I. Yoo, B.H. Kim and J.-K. Park, "Transmission embedded cost allocation methodology with consideration of system reliability", IEE Proc.-Gener. Transm. Distrib., Vol. 151, No. 4, July 2004.

[16] HUR D., YOO C.I., KIM B.H., PARK J.K.: 'Transmission embedded cost allocation methodology with consideration of system reliability', IEE Proc., Gener. Trans. Distrib., 2004, 151, (4), pp. 427432.

[17] V. Vijay Venu, A. K. Verma, "A probabilistic transmission pricing methodology considering transmission reliability margins”, Int J Syst Assur Eng Manag (Apr-June 2010) 1(2):113-119.

[18] Monsef H, Jaefari M, "Transmission cost allocation based on use of reliability margin under contingency conditions", IET Gener Transm, Distrib 3(6):574-585. 
Electrical \& Computer Engineering: An International Journal (ECIJ) Volume 2, Number 3, September 2013

[19] Rohit Bhakar, V. S. Sriram, Narayana Prasad Padhy and Hari Om Gupta, "Probabilistic Game Approaches for Network Cost Allocation,” IEEE Transactions on Power Systems, Vol. 25, No. 1, pp. 51-58, February 2010.

[20] Ahiakwor C.O., Chukwu U.C., Dike D.O., "Optimal transmission line pricing algorithm for a restructured power system”, Transmission and Distribution Conference and Exposition, 2008, 21-24 April 2008.

[21] Narsingh Deo, "Graph Theory with Applications to Engineering and Computer Science”, PrenticeHall of India, 1994, pp. 220-227.

[22] Rohit Bhakar, V. S. Sriram, N. P. Padhy, H. O. Gupta, "Network Embedded Cost Allocation: A Game Theoretic Approach”, 32ed National Systems conferences, (NSC 2008), Dec. 17-19, 2008.

[23] Adam Brandenburger, "Co-operative Game Theory: Characteristic Function Allocations, Marginal Contribution", version 01/04/07.

[24] C.W.Yu, A.K.David and Y.K.Wong, "The Use of Game Theory in Transmission Embedded Cost Allocation", Proceedings of the 5th International Conference on Advances in Power System Control, Operation and Management (APSCOM 2000), Hong Kong, October 2000.

[25] Du SongHuai; Zhou Xinghua; Mo Lu; Xue Hui; , "A novel nucleolus-based loss allocation method in bilateral electricity markets," Power Systems, IEEE Transactions on , vol.21, no.1, pp. 28- 33, Feb. 2006.

[26] Wood, A.J., and Wollenberg, B.F.: 'Power generation, operation, andcontrol' (Wiley, New York, 1996, 2nd Edn.).

[27] Orfanos, G.A.; Georgilakis, P.S.; Hatziargyriou, N.D., "A More Fair Power Flow Based Transmission Cost Allocation Scheme Considering Maximum Line Loading for N-1 Security," Power Systems, IEEE Transactions on , vol.28, no.3, pp.3344,3352, Aug. 2013

\section{Authors}

Baseem Khan was born in Gwalior, India in 1987. He received BE degree (2008) from Maharana Pratap College of Technology Gwalior and received an M.Tech. degree (2010) in Power System from MANIT Bhopal. At the moment he is a research scholar at MANIT Bhopal, India.

Ganga Agnihotri received BE degree in Electrical engineering from MACT, Bhopa 1 (1972), the ME degree (1974) and PhD degree (1989) from University of Roorkee, India. Since 1976 she is with Maulana Azad College of Technology, Bhopal in various positions. Currently she is professor. Her research interest includes Power System Analysis, Power System Optimization and Distribution Operation.

Gaurav Gupta was born in chhatarpur, India in 1985. He has received degree in 2006 from MITS Gwalior and received ME degree2009 in power electronics from SGSITS indore. At present he is a research scholar in MANIT Bhopal, India.
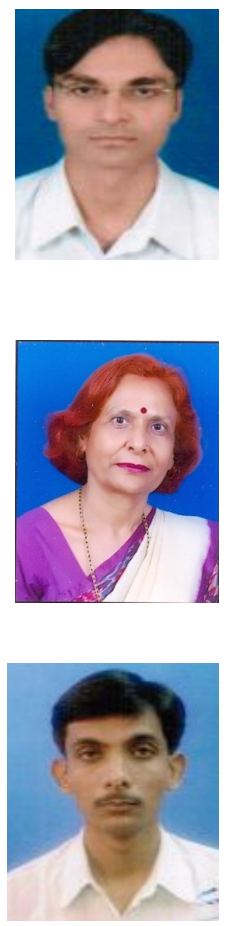